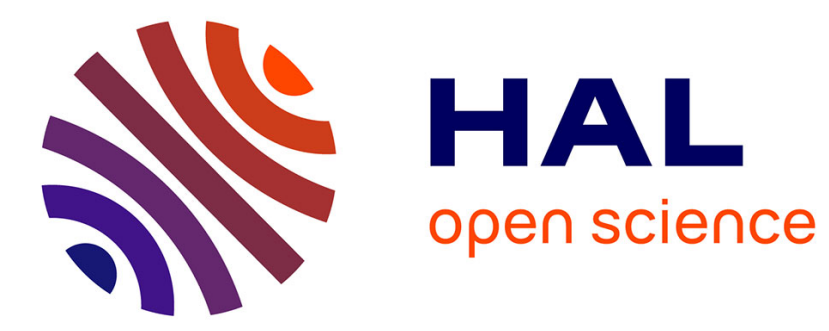

\title{
The Distinct Effect of Multiple Sources of Stereotype Threat
}

\author{
Caroline Desombre, Mickaël Jury, Céline Bagès, Célénie Brasselet
}

\section{To cite this version:}

Caroline Desombre, Mickaël Jury, Céline Bagès, Célénie Brasselet. The Distinct Effect of Multiple Sources of Stereotype Threat. Journal of Social Psychology, 2019, 159 (5), pp.628-641. 10.1080/00224545.2018.1544540 . hal-01908262

\section{HAL Id: hal-01908262 \\ https://hal.science/hal-01908262}

Submitted on 12 Nov 2018

HAL is a multi-disciplinary open access archive for the deposit and dissemination of scientific research documents, whether they are published or not. The documents may come from teaching and research institutions in France or abroad, or from public or private research centers.
L'archive ouverte pluridisciplinaire HAL, est destinée au dépôt et à la diffusion de documents scientifiques de niveau recherche, publiés ou non, émanant des établissements d'enseignement et de recherche français ou étrangers, des laboratoires publics ou privés. 


\title{
The Distinct Effect of Multiple Sources of Stereotype Threat*
}

\author{
Caroline Desombre ${ }^{1, *}$, Mickaël Jury ${ }^{2}$, Céline Bagès $^{3}$, and Célénie Brasselet ${ }^{1}$
}

\author{
${ }^{1}$ ESPE Lille Nord de France and Univ Lille-Nord de France, PSITEC - EA 4072 \\ ${ }^{2}$ ESPE Clermont Auvergne, ACTé - EA 4281 \\ ${ }^{3}$ Univ Lille-Nord de France - EA 4072 \\ *caroline.desombre@espe-Inf.fr
}

\begin{abstract}
Stereotype threat (ST) refers to the risk of confirming a negative stereotype about one's group. Distinct forms of ST can be elicited based on both the target and the source of the threat. Here, we focused on how peculiar ST sources distinctly impact performance for individuals who face self-based threats. More particularly, we hypothesized that the decrease in performance would be stronger for individuals who face a self-concept threat (triggered by a private self-evaluation) in comparison with those who face an own-reputation threat (triggered by a public evaluation). In two studies, participants were randomly assigned to one of the following experimental conditions: control, self-concept or own-reputation threat. Results confirmed the hypothesis by showing that participants in the control condition perform better than those in the own-reputation threat condition, who performed better than those in the self-concept threat condition. The contributions of this work as well as the limitations are discussed.
\end{abstract}

\section{Introduction}

The stereotype threat phenomenon has received a great deal of attention in social psychology literature (for recent reviews see Pennington, Heim, Levy, \& Larkin, 2016; Spencer, Logel, \& Davies, 2016). Stereotype threat (ST) is a phenomenon known to impair the performance of members from stereotyped groups in contexts where the negative reputation associated with these groups is salient (Steele, 1997). The ST has been usually demonstrated for stigmatized groups (e.g., Afro-Americans, unemployed people, homosexuals, see Bosson, Haymovitz, \& Pinel, 2004; Bourguignon, Desmette, Yzerbyt, \& Herman, 2007; Steele \& Aronson, 1995) but also for non-stigmatized groups (e.g., white men in sports, Stone, Lynch, Sjomerling, \& Darley, 1999; men regarding their emotional expression, Leyens, Désert, Croizet, \& Darcis, 2000; for other examples, see Aronson, Lustina, Good, Keough, \& Brown, 1999; Koenig \& Eagly, 2005; Pansu et al., 2016). In addition, ST is known to affect one's performance in various domains (e.g., mathematics, intellectual abilities, sports, social task, childcare skills, performance in chess; for examples see Bagès \& Martinot, 2011; Bosson et al., 2004; Chalabaev, Sarrazin, Stone, \& Cury, 2008; Desombre, Anegmar, \& Delelis, 2018; Kray, Thompson, \& Galinsky, 2001; Maass, D’Ettole, \& Cadinu, 2008; Spencer, Steele, \& Quinn, 1999). Further developments in this field proposed a multi-threat framework assuming that there are six different ST that should be considered (see Shapiro, 2011, 2012; Shapiro \& Neuberg, 2007). However, very few works investigated the consequences associated with these distinct forms of ST. In line with this framework, the present paper proposes to specifically investigate the impact of two different forms of these STs: The self-concept and the own-reputation - ingroup - threat.

\section{From a Single to Multiple Threats}

ST can increase evaluative pressures on any individual when the situation invokes a stereotype-based expectation of poor performance and implies that other people may view them stereotypically (Blascovich, Spencer, Quinn, \& Steele, 2001). In their seminal experiment, Steele and Aronson (1995) showed that African American college students underperformed on standardized tests in relation to their white peers when the task was presented as a diagnostic of their verbal ability. This difference was not observed when the participants were told that the purpose of the study was to better understand the psychological factors involved in solving verbal problems (i.e., non-diagnostic condition). Performance impairment was explained by the evaluative pressure created by the possibility of confirming the negative stereotype about African Americans' intelligence. For decades, this phenomenon was studied as a single construct. Interestingly, in 1997, Steele (p. 618) had already proposed that, "Different groups experience different forms and degrees of ST because the stereotypes about them differ in content, in scope, and in the situations to which they apply". Such a possibility of multiple forms of ST was taken up by Aronson and colleagues (1999) and was then documented by Shapiro and her colleague Neuberg (Shapiro, 2011, 2012; Shapiro \& Neuberg, 2007). In 2007,

\footnotetext{
${ }^{*}$ This paper has been accepted for publication in The Journal of Social Psychology on the 4th of October 2018. This version is thus a postprint.
} 
Shapiro and Neuberg proposed a multi-threat framework which identified qualitatively distinct core STs. This model specifies that individuals can experience a variety of threats depending on the intersection of two dimensions (Shapiro \& Aronson, 2013; Shapiro \& Neuberg, 2007): the target of the threat (i.e., the self or one's group, "Will one's actions reflect upon the self or one's group?") and the source of the threat (i.e., the self, outgroup others, or ingroup others, "Who has the opportunity to use these actions as an indication of ability: the self, outgroup others or ingroup others?"). According to Shapiro and Neuberg (2007), such an intersection results in six different forms of ST (see Table 1): a threat to one's self-concept (i.e., the fear of confirming in one's mind that the stereotype is true for him/her; a self-concept threat); a threat to one's personal reputation in ingroup others' eyes (i.e., the fear of confirming in ingroup members' eyes that the stereotype is true for him/her; an own-reputation - ingroup - threat); a threat to one's personal reputation in outgroup others' eyes (i.e., the fear of confirming in outgroup members' eyes that the stereotype is true for him/her; an own-reputation - outgroup - threat); a threat to one's group concept (i.e., the fear of confirming in one's mind that the stereotype is true for his/her group members; a group-concept threat); a threat to one's group reputation in ingroup others' eyes (i.e., the fear of confirming in ingroup members' eyes that the stereotype is true for his/her group members; a group-reputation - ingroup - threat); and a threat to one's group reputation in outgroup others' eyes (i.e., the fear of confirming in outgroup members' eyes that the stereotype is true for his/her group members; a group-reputation - outgroup - threat).

\begin{tabular}{ccc}
\hline & \multicolumn{2}{c}{ Target of the Threat } \\
\cline { 2 - 3 } Source of threat & Self & Group \\
\hline Self & Self-concept threat & Group-concept threat \\
Out-group members & Own-reputation - outgroup - threat & Group-reputation - outgroup - threat \\
\hline
\end{tabular}

Table 1. Different forms of ST according to the model of Shapiro and Neuberg (2007).

The following research identified that these different threats can be activated by different variables (e.g., level of identification, endorsement of the stereotype, contextual incentives, see Shapiro, 2011, 2012). For example, Shapiro (2011) showed that individuals stigmatized as a function of their mental health, weight, race/ethnicity, and religion experience a different ST pattern. More precisely, individuals from groups that tend to elicit low stereotype endorsement (e.g., religion, or race/ethnicity) were less likely to report experiencing self-as-source STs than others-as-source STs. In comparison, groups that tend to elicit low group identification (e.g., mental illness, obesity) were less likely to report experiencing group-as-target STs than self-as-target STs (for other examples, see Carels et al., 2013; Laurin, 2017; Oliveira \& Cabral-Cardoso, 2017). However, and maybe more importantly, few researches have illustrated that one's performance decrement can depend on one type of the threats previously mentioned.

\section{Different Stereotype Threats and Decrement of Performance}

Few studies have shown that the target of threat could have distinct effects on one's performance (Wout, Danso, Jackson, \& Spencer, 2008; Zhang, Schmader, \& Hall, 2013). For example, Wout et al. (2008) investigated the effect of two types of threat on women's performance: A self-concept threat (i.e., the concern about confirming that a negative stereotype about oneself is true) and a group-reputation threat (i.e., the concern about confirming that a negative stereotype about their gender is true). These threatening conditions were compared to a "classic" threatening condition (i.e., a "diagnostic" condition in Study 1) and a control condition (i.e., a "non-diagnostic" condition in both studies). The results from the first study showed that women's math performance was differentially affected by the target of the threat. Participants in the self-concept threat condition performed worse than those in the control condition, but no performance differences were observed between participants in the control condition and those in the group-reputation threat condition. In the second study, results followed a similar pattern but illustrated that group- and self-based threats have distinct moderators. Indeed, gender identification moderated the effect of the group-reputation threat condition on test performance (i.e., the more participants identified with their gender, the more their performance was impaired in this condition) but not the effect of the self-based threat. In the same way, Zhang et al. (2013) explored the effect of threat target on women's math performance. In a pilot study, they demonstrated that women's concerns about confirming the stereotype are more important in a self-reputation threat condition than in a group-reputation threat condition. In the primary study, the threat target was manipulated while the source was consistently maintained as "others" (i.e., the performance was public in all conditions). The threat target was manipulated through the bond between self and performance. In an own-name condition, participants were asked to write the date, their real name and their gender on a math test booklet cover sheet. In an identity-masked condition, they were instructed, namely for coding purposes and due to confidentiality concerns, to indicate a fictitious name on each page of the math test. The fictitious name was assigned and could either be male or female. In this condition, participants were thus primed with the idea that the self would not be publicly linked to their performance. The results showed that women in a self-based threat condition (that produced more own-reputation 
thoughts than the control condition) performed worse than both women in a control condition and women in an identity mask condition (participants used a fictitious name). Men were unaffected by these conditions. Thus, these studies confirm that one's performance could be distinctly influenced by ST forms varying as a function of the target. Nonetheless, to our knowledge, no study has been conducted regarding potential distinct effects of ST as a function of the source of the threat. However, according to Shapiro and Neuberg (2007), the performance context (i.e., public or private) could also influence the experience of both other-as-source ST (i.e. for self-as-target, own-reputation - ingroup- threat, own-reputation - outgroup - threat) and self-as-source ST (i.e., for self-as-target, the self-concept threat). If most studies in ST literature were conducted in public settings (see for examples Desombre et al., 2018; Steele, \& Aronson, 1995; Wout et al., 2008; Zhang et al., 2013), the hypothesis that ST can appear in private settings has also received some attention (Inzlicht \& Ben-Zeev, 2003; Larkin \& Pines, 2011; Sekaquaptewa \& Thompson, 2003; Stone, 2002). Steele and Aronson (1995) argued that private self-evaluation, in addition to public situations, can trigger ST (see also Steele, 1997). However, results regarding this issue are not very compelling. For example, Larkin and Pines (2011) manipulated the context (public or private). In the public condition, participants anonymously completed the test but were told that their personal results would become public. In the private condition, participants also completed alone the test but were told that no one else would access their results. In this study, the authors demonstrated that women in public settings experienced a higher degree of threat than men in a similar context; no difference appeared in a private context. Contrarily, Inzlicht and Ben-Zeev (2003) showed that women were equally impacted by a threatening condition in either a public (i.e., performance was allegedly public and openly evaluated by their partners) or a private context (i.e., performance was allegedly anonymous) in comparison with women in a non-threatening condition. Such a result led the authors to argue that ST processes "may also come about through intrapsychic processes, such as self-evaluation" (p.801), namely in private settings. Despite these scarce results, the present paper sought to specifically test that the decrement in performance observed in ST literature could be stronger for individuals who face a self-concept threat compared to those who face an own-reputation threat ${ }^{1}$. Indeed, we notably thought that a self-concept threat condition could trigger participants' private self-consciousness (i.e., a focus on the more covert and personal aspects of oneself) to a greater extent compared to the own-reputation threat condition - which should instead trigger participants' public consciousness (i.e., an awareness of the self as a social object). Since in private settings, individuals' concerns are more focused on the desire to hold themselves in high regard, to not disappoint themselves and to perform well (Inzlicht \& Ben-Zeev, 2003), we hypothesized that when the self is specifically targeted (i.e., the fear of confirming in one's or ingroup's mind that the stereotype is true for him/her), the fear of being judged or treated badly in such a situation would be more likely to reduce performance in comparison with a public evaluation. Indeed, in public settings, ST usually emerges from the desire to look good in the eyes of others (Steele, 1997). In others words, when the self is targeted and when the source of this threat is own self (i.e., the self-concept threat), we hypothesized that participants would experience more intensively the negative emotional state associated with the threatening situation (for an example see Scheier \& Carver, 1977) in comparison with a situation in which the self is targeted but the source is others (i.e., the own-reputation threat condition). It should be noted that congruently with the ST literature, we expected that participants in this last condition would still experience a ST, which should lead them to perform worse than those in a control condition. Consequently, we expected that participants in the control condition would perform better than those in the own-reputation threat condition, whom perform better than those in the self-concept threat condition. Two experiments tested this hypothesis. Databases can be accessed at: https://osf.io/wjsdv/.

\section{Experiment 1}

\section{Method \\ Participants.}

Sixty-seven 9th graders from the same public high-school (located in the north of France) participated to this experiment without financial or any other forms of compensation. Before data collection, both the school headmaster and students' parents gave their agreements. In addition, students had the opportunity to refuse to participate after receiving initial information. The final sample included 66 participants (i.e., one participant was excluded because he did not report his previous grade in mathematics), 37 boys and 29 girls $(M=14.15, S D=0.36)$. According to their teachers, participants did not suffer from the disability involved here to manipulate STs (i.e., hearing impairment).

\section{Procedure and Material.}

The male researcher gave minimal explanation regarding the purpose of the experiment and provided instructions to complete the task in participants' classroom. These instructions differed according to the condition in which participants were randomly assigned to. After performance task, participants completed demographics information and then were fully debriefed.

Stereotype threat manipulation. Participants were randomly assigned to one of the three experimental conditions. Participants in the threatening conditions (i.e., self-concept threat and own-reputation threat) were told that the aim of the experiment

\footnotetext{
${ }^{1}$ It should be noted that in the present study, we will not focus on the own-reputation (outgroup) threat.
} 
was to evaluate and compare the attentional abilities of students with and without disability (i.e., hearing impairment ${ }^{2}$ ). It should be noted that the researcher was an individual without hearing impairment, i.e. an ingroup member. Participants in the ST conditions specifically heard: "In general, people with hearing impairment performed better on attention and concentration tests than people without hearing impairment." The experiment was then presented as a way to understand the reasons underlying this difference. As such, participants were informed that they had to complete a task assessing these abilities. Congruently with classical paradigm in this field (see Wout et al., 2008), participants in the self-concept threat condition $(N=25)$ were informed that their performance would remain private, i.e., participants were led to think that noone except them would be informed of their performance and that they would keep their answer sheet. Participants were told that:"For this test, you will be the only one to know your result. That is, we will not get it. You will be able to evaluate yourself and be the only one to know your result. Therefore, you will keep your answer sheet. To allow you to compare yourself to deaf participants, we will give you their average score". In the own-reputation threat condition $(N=20)$, participants were informed that the researchers, but not themselves, would have access to their performances. Participants heard: "For this test, you will not know your result. We will be the only ones to know them. That is, we will evaluate your test individually and know if your score is different from the one obtained by deaf participants. Therefore, you have to indicate your first and last name in order to allow us to compare your personal score to the deaf people' score. We will personally be able to compare yours to them. In order to do so, we will need to collect your answer sheet". After task completion, participants were fully debriefed regarding the goal and the experimental manipulation of the experiment and were informed that the researchers will therefore need to collect all the sheets from every participant in order to test their hypotheses. Participants in the control condition $(N=21)$ only received the instructions to complete the task but did not receive any information about the comparison with individuals with hearing impairments. No mention of disability was made. They were aware of the fact that the researcher would collect the answer sheets at the end of the experiment. These participants received the same debrief.

Performance. Participants completed 28 items from the Progressive Matrices (i.e., the D-series Raven, Raven, \& Court, 1998/2003). Each item depicts an abstract pattern in a 3 x 3 matrix. All cells contain a figure except the one in the bottom-right corner. Participants had to find the figure that complete the pattern correctly. Individuals' performance represents the sum of the correct answers $(M=8.02, S D=3.19)$.

Participants' level of competence. Since one's level of academic competence is traditionally associated with one's level of performance in the Progressive Matrices (see Laidra, Pullmann, \& Allik, 2007), the influence of such a variable was controlled. Participants' level of competence in mathematics (i.e., their grade) was provided by their teachers $(M=12.40, S D=3.43)$ and added to the statistical model.

\section{Results and Discussion}

Participants in the control condition were expected to perform better than participants in the own-reputation threat condition, whom were expected to perform better than participants in the self-concept threat condition. Due to the specificity of our hypothesis, we have decided to conduct contrast analyses (see Brauer \& McClelland, 2005). Indeed, "precise conclusions can be obtained from contrast analysis because a contrast expresses a specific question about the pattern of results of an Anova" (see Abdi \& Williams, 2010, p. 253). Therefore, the regression model tested two contrasts: The first contrast (i.e., the contrast of interest) tested a linear relation and compared the self-concept threat condition (coded -1), the own-reputation threat condition (coded 0 ), and the control condition (coded +1 ). The second contrast (i.e., the orthogonal contrast) compared the own-reputation threat condition (coded +2 ) to the self-concept threat condition and the control condition taken together (coded - 1 respectively). Participants' level of competence in mathematics (mean-centered) was entered as a covariate. Thus, the final model integrated three predictors. It should be noted that preliminary analysis in both experiments were conducted in order to test a potential unexpected - main effect of sex. Since results revealed no effects (all $p s>.53$ ), this variable was not retained in the analysis.

\section{Performance.}

The analysis revealed a significant effect of the first contrast, $B=1.09, S E=.43, t(62)=2.51, p=.015, \eta_{p}^{2}=.09,95 \% \mathrm{CI}$ $[0.22,1.94]$, whereas the second contrast was not significant, $B=-0.28, S E=.26, t(62)=-1.08, p=.28, \eta_{p}^{2}=.01,95 \% \mathrm{CI}$ $[-0.80,0.24]$. As illustrated on Figure 1, this analysis confirmed that participants in the control condition $(M=9.42, S E=$ .64) performed better than participants in the own-reputation threat condition $(M=7.49, S E=.66)$ who performed better than participants in the self-concept threat condition $(M=7.25, S E=.58)$.

It is worth noting that participants' level of competence positively predicted participants' performance at the matrices, $B=$ $0.29, S E=.11, t(62)=2.73, p=.008, \eta_{p}^{2}=.10,95 \%$ CI $[0.07,0.50]$, and that the effect of the first contrast remained significant when the influence of this variable was not controlled, $B=1.10, S E=.45, t(63)=2.43, \mathrm{p}=.018, \eta_{p}^{2}=.08,95 \% \mathrm{CI}[0.19,2.00]$.

\footnotetext{
${ }^{2}$ For these two studies, the type of disability was not important. The purpose of these experimental manipulations was to examine the ST effect through an identity rarely activated in order to limit the influence of participants' history within one domain. This choice was driven by the will to strictly examine the effect of the different ST. Nonetheless, as evoked in the general discussion, this choice could have also generated some issues for consideration in future studies.
} 


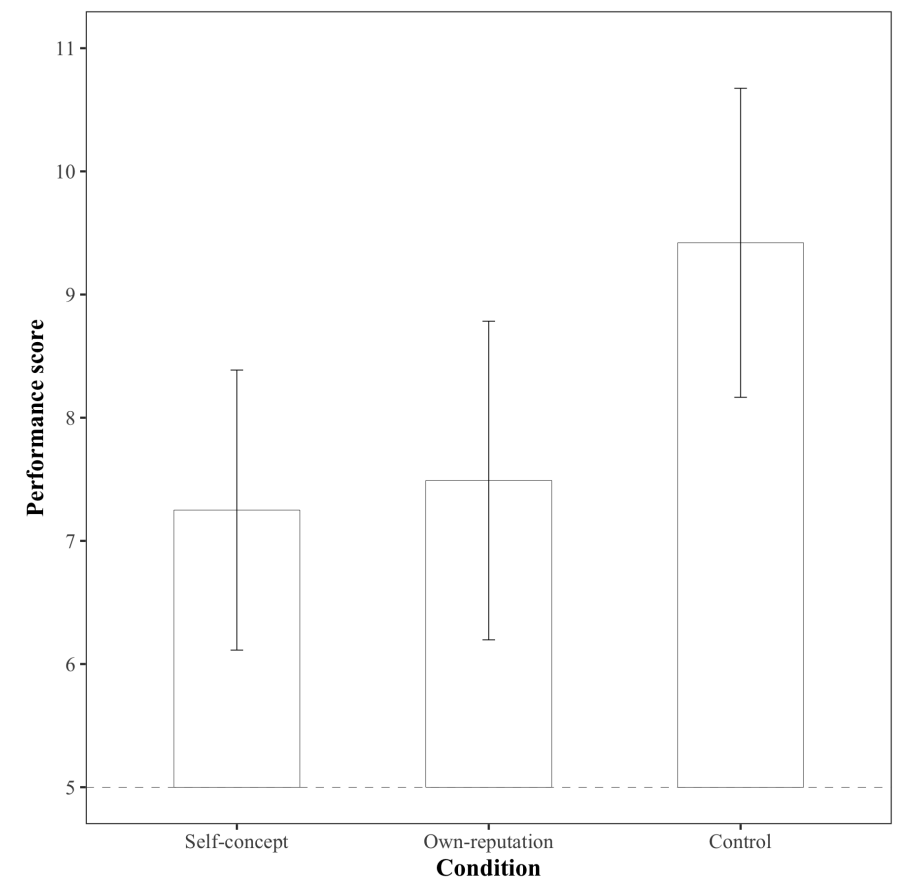

Figure 1. Mean performance at the Progressive Matrices depending on the experimental condition. Errors bars represent $95 \%$ CIs.

Based on the framework from Shapiro and Neuberg (2007), we argued that participants would be more sensitive to a self-concept threat that confirms in his/her mind the unfavorable comparison with the other group, in comparison with an own-reputation threat, which confirms in the eyes of ingroup others the unfavorable comparison with the other group. The results confirmed that distinct threatening environments elicited distinct performance decrements. Indeed, as expected, participants in the self-concept threat condition (triggered by a private self-evaluation) performed worse than those in the own-reputation threat condition (triggered by a public evaluation), whom performed worse than those in the control condition. However, it should be noted that despite our will to create a condition in which participants were led to think that they would not have any information on their personal performance (i.e., the own-reputation threat condition), it cannot be excluded that participants in this condition were minimally able to evaluate their level of performance. As a result, these participants might also have suffered from a self-concept threat. Such a situation may explain the slight difference between the two conditions and the difficulty to disentangle the specific effect of the own-reputation threat condition. The second experiment was notably designed to solve this issue and to replicate these results.

\section{Experiment 2}

\section{Method}

\section{Participants.}

Sixty participants (37 women and 23 men) were recruited on a university campus or nearby (also located in the north of France). The participants came from various backgrounds and agreed to participate to this experiment without financial or any other forms of compensation. The age range was wide, from 17 to $70(M=37.32, S D=15.37)$. Before data collection, participants signed a consent form. Participants did not suffer from the disability involved here (i.e., visual impairment).

\section{Procedure and Material.}

Participants were tested individually and were randomly assigned to one of the three experimental conditions. The researcher explained that the experiment dealt with memory performance and gave general and specific instructions depending on the experimental condition (see below). Then, participants were asked to listen twice a list of twenty-nine words prerecorded on a microphone (e.g., "cellar", "guest", "book", "computer"). Immediately after hearing it, they recalled as many words as possible under a time constraint (i.e., 4 minutes). Following the memory test (i.e. number of words properly recalled), demographic questions (including the presence or absence of a visual impairment) were completed and participants were fully debriefed about the purpose of the experiment. As in the first experiment, the deception was fully disclosed notably in order to collect the 
answers of participants in the self-concept threat condition.

Stereotype threat manipulation. Participants in the threatening conditions (i.e., self-concept threat and own-reputation threat) were told that the aim of the experiment was to evaluate and compare memory performances of people with and without disability (i.e., visual impairment) and that the experiment represent a way to understand the reasons sustaining such differences ${ }^{3}$. As in the first experiment, the female researcher was an ingroup member with no visual impairment. Participants in the self-concept threat condition $(N=20)$ were then told that their performance would remain private: they would be the only ones to know about it and that they would keep their answer sheet. Participants in the own-reputation threat condition $(N=$ 20) were told that their performance would be known by the research team and that they would not receive any information about it. In order to limit participants' potential estimation of their performance, and thus a potential self-concept threat, they were led to believe that their score did not depend on the number of words. More precisely, participants were told that "This memory test is a special test. The test score is not linked with the number of recalled words but with the words themselves. So, don't try to estimate your performance, it is not possible." Finally, participants in the control condition $(N=20)$ only received the instructions to complete the task and no mention of disability (i.e., visual impairment) was made.

Performance. The number of words correctly recalled represented participants' performance $(M=10.52, S D=3.24)$.

Participants' level of competence. Due to the heterogeneity of the sample, participants' level of competence was inferred through their level of education. Indeed, the correlation between one's level of education and one's memory span is robust (Orsini et al., 1987). Therefore, participants were asked to report the number of years they studied in higher education. On average, participants studied 2.53 years after their high-school graduation $(S D=1.87)$.

\section{Results and Discussion}

Similarly, as within the first experiment, participants in the control condition were expected to perform better than participants in the own-reputation threat condition, whom were expected to perform better than participants in the self-concept threat condition. Therefore, the regression model tested the same set of contrasts. As previously, the former compared the self-concept threat condition (coded -1), the own-reputation threat condition (coded 0 ), and the control condition (coded +1$)$ and the latter compared the own-reputation threat condition $($ coded +2$)$ to the self-concept threat condition and the control condition (coded -1 respectively). As in the first study, participants' level of academic achievement (mean-centered) was also entered in the model. Nonetheless, since preliminary analysis revealed that it did not significantly predict performance, $B=0.30, S E=.19$, $t(56)=1.59, p=.12, \eta_{p}^{2}=.04,95 \% \mathrm{CI}[-0.07,0.68]$, this variable was removed from the final model. Thus, this one only integrated the two contrasts as predictors. Number of words recalled. As expected, the analysis revealed a significant effect of the first contrast, $B=2.15, S E=.43, t(57)=5.01, p<.001, \eta_{p}^{2}=.30,95 \% \mathrm{CI}[1.29,3.01]$, whereas the second contrast was not significant, $B=-0.33, S E=.25, t(57)=-1.34, p=.18, \eta_{p}^{2}=.03,95 \% \mathrm{CI}[-0.83,0.16]$. As shown on Figure 2, participants in the control condition $(M=13.00, S E=.61)$ performed better than participants in the own-reputation threat condition $(M=9.85, S E$ $=.61)$, whom performed better than those in the self-concept threat condition $(M=8.70, S E=.61)$. It is worth noting that with participants' level of competence included in the analyses the effect of the first contrast remained significant, $B=2.16, S E=$ $.42, t(56)=5.09, p<.001, \eta_{p}^{2}=.31,95 \%$ CI $[1.30,3.00]$, while the second was not, $B=-0.41, S E=.25, t(56)=-1.65, p=.11$, $\eta_{p}^{2}=.04,95 \%$ CI [-0.91, 0.08].

The purpose of this second experiment was to replicate results from the first experiment and correct for a potential methodological issue presented in one of the experimental condition (i.e., the own-reputation threat condition). Results from this second experiment confirmed those obtained in the first. Indeed, Study 2 supported that individuals who faced a self-concept threat were more exposed to performance disruptions than individuals who faced an own-reputation threat.

\section{General Discussion}

ST corresponds to the risk of confirming a negative stereotype about one's identity and is associated with a reduction of performance for those who face this situational identity threat (for a review see Pennington et al., 2016). Based on the multi-threat framework (Shapiro \& Neuberg, 2007), previous research has shown that this decrement can vary according to the target of threat. More precisely, Wout et al. (2008, see also Zhang et al., 2013) demonstrated that women's performance on a mathematical task was more affected by a ST in which they were the target (i.e., a self-concept threat) in comparison with a ST in which their group was the target (i.e., a group-reputation threat). Nonetheless, to our knowledge, no study has investigated potential distinct ST effects dependending on the source of the threat (i.e., one self, ingroup or outgroup members).

\footnotetext{
${ }^{3}$ A pilot study was conducted to verify the stereotype awareness of visual impairment and memory. Forty-nine French participants without sensory impairment aged from 17 to $69(M=39, S D=11.5)$ were asked to estimate the level of memory performance of people with and people without visual impairment (on a 7-point Likert-type scale, from 1, "rather poor" to 7, "rather excellent"). A stereotype awareness score was calculated by computing a difference between these two estimations (Bonnot \& Croizet, 2007). The result confirmed stereotype awareness since participants estimated that people with visual impairment $(M=6.37, S D=.70)$ have a higher level of memory performance than people without visual impairment $(M=4.45, S D=.79)$. This difference was statistically different from zero, $t(48)=17.08 ; p<.001$.
} 


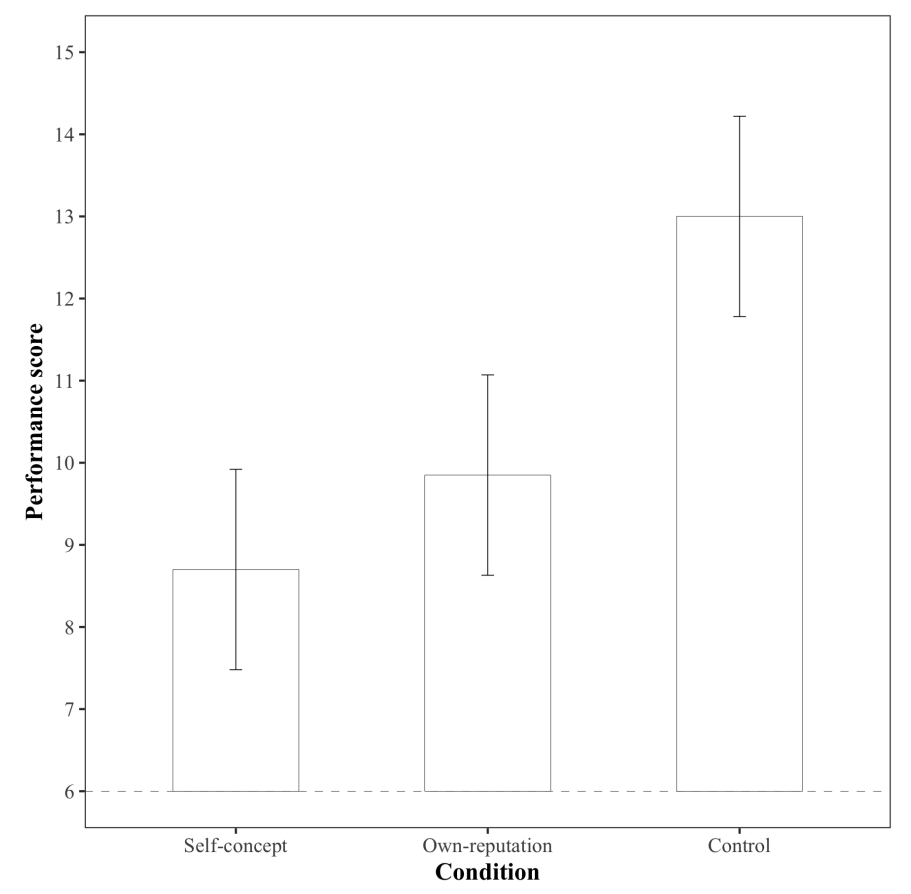

Figure 2. Mean performance at the memory task depending on the experimental condition. Errors bars represent $95 \%$ CIs.

Here, we argued that if ST conditions should elicit a performance decrement in comparison with a control condition, such a decrement would be larger for participants who face a self-concept threat - triggered by private evaluation - in comparison with those who face an own-reputation threat - triggered by public evaluation. Two experiments tested these hypotheses and confirmed that participants who faced a self-concept threat were those who suffer the most from ST. In line with Steele's (1997) initial proposition, these results confirm that individuals can face different forms and degrees of ST, and that these forms and degrees can distinctly affect one's performance. Therefore, in addition to the variation depending on the target of the ST (Wout et al., 2008; Zhang et al., 2013), the present results confirmed that the ST effect could also vary as a function of the type of source. Indeed, depending on the instructions formulated by the researchers, different types of ST could be activated, resulting in more or less threatening situation for the participants. The present research supported that the ST effect is more complex than expected and should contribute to explain why its magnitude varies in literature. Thus, a critical examination of the specific effects of each ST seems necessary. However, it is worth noting that this work is not without limitations, implying that the conclusions drawn from the present findings should be read carefully. First, despite moderate effect sizes in both studies, it should be acknowledged that sample sizes are particularly small in both studies and that further replications with a higher number of participants are absolutely necessary to strengthen the present results. On a related statistical aspect, it should be acknowledged that even if the contrast analyses used here seem to confirm the linear tendency expected between our experimental conditions, the difference between the ST conditions are particularly small. Second, it should be noted that ST studies usually focus on stigmatized individuals (based on their gender or race). However, in these two studies, we have decided to threaten a usually non-stigmatized group (i.e., non-disabled individuals) by referring to negative stereotypes about some cognitive performances (i.e., attention and memory). Although one's history of non-stigmatization and/or high status do not necessarily act as a protection from experiencing ST (Leyens et al., 2000), it should be acknowledged that the literature on intergroup relations showed that low-status individuals (e.g., women, ethnic minorities, low-SES individuals) are more likely to face stereotypes (Berger, Cohen, \& Zelditch, 1972; Fiske, Cuddy, Glick, \& Xu, 2002) and to self-stereotype in comparison with high-status individuals (Simon \& Hamilton, 1994). As a result, since high-status individuals suffer less from stereotypes and could benefit from other positive identities to overcome ST in comparison with low-status ones (for an example on how multiple identities can protect from ST, see Ambady, Shih, Kim, \& Pittinsky, 2001), a ST involving their group might be less threatening for them than for low-status individuals. Moreover, the underlying processes behind performance decrement may be different for high status groups compared to usually stigmatized groups (Cadinu, Maass, Frigerio, Impagliazzo, \& Latinotti, 2003). Indeed, for high status individuals, ST in laboratory can be viewed as a new experience and the fear of confirming negative stereotypes in others' eyes could be less salient. Consequently, a ST originating from others may be less threatening than a ST coming from themselves. On the contrary, for stigmatized group, ST situations could activate prior experiences of 
discrimination and may reinforce their low status, resulting in greater fear of being judged by others than by themselves. Thus, since one's status could also moderate the effects of these distinct forms of ST, our findings must be read carefully and may not be fully applied to usually stigmatized groups. Future studies should replicate our results with such groups. Third, the present studies have not investigated any underlying mechanisms that may explain why the magnitude of the threat is larger for participants in the self-concept threat condition compared with those in the own-reputation threat condition. For example, future studies could examine the extent to which self-based intrusive thoughts are activated distinctly within these two self-based threats conditions. Investigating underlying mechanisms could also exclude alternative explanations to our results such as the effect of social comparison or stereotype priming. Fourth and finally, it should be acknowledged that ST and its importance in real-life setting could be questioned. Indeed, even if many reviews and meta-analyses confirmed the robustness of this effect (Doyle \& Voyer, 2016; Picho, Rodriguez, \& Finnie, 2013), ST should not be interpreted as responsible for long-term differences between subgroups on test scores at school or in the workplace (Sackett, Hardison, \& Cullen, 2004; Stoet \& Geary, 2012). According to the same authors, numerous misinterpretations of Steele and Aronson's work have led to overestimate the effect of ST on economic differences in our societies. Other factors, such as differences in educational and economic opportunities of minority groups can significantly contribute to intergroup inequalities. Therefore, the conclusions associated with the present work should be read carefully. Notwithstanding these limitations, by showing that ST can distinctly affect one's performance depending on the source, this work also raises questions for future research. As mentioned above, specific moderators could be considered depending on the types of source/target of threat. For example, gender identification moderated the effect of group-based threat on performance but not the effect of self-based threat (Wout et al., 2008). In the same way, stereotype endorsement and stigma consciousness could probably act as distinct moderators for the effect of other-as-source ST and self-as-source ST (Shapiro \& Neuberg, 2007). For example, these authors argued that self-concept threat should mostly emerge when an individual think that the stereotype could be true for his personal abilities. Hence, stereotype endorsement could act as a moderator for this kind of ST but not for other-as-source ST. Additionally, since some personal characteristics such as private and public self-consciousness or self-esteem are known to be related to stereotype endorsement (for example, see Lysaker, Tsai, Yanos, \& Roe, 2008), they could also affect differently performance depending on the source of the threat. Future studies should test these hypotheses. Finally, since self-affirmation abilities are known to disrupt ST (Martens, Johns, Greenberg, \& Schimel, 2006), it might be possible that this could be particularly the case in self-as-source ST in comparison with other-as-source ST. If some moderators are specific to certain types of threats, it could therefore explain why some reviews and meta-analyses failed to replicate the moderating effect of different variables (Doyle \& Voyer, 2016; Flore \& Witcherts, 2015; Lamont, Swift, \& Abrams, 2015; Nguyen \& Ryan, 2008; Régner, Steele, Ambady, Thinus-Blanc, \& Huguet, 2014). In the same way, it has also been suggested that the literature regarding the mechanisms underlying the ST phenomenon (for a review of theses, see Schmader, Johns, \& Forbes, 2008) may sometimes lack empirical support (Pennington et al., 2016). However, possible reasons for this situation can be that mediators vary according to the type of ST faced by an individual (Shapiro \& Neuberg, 2007; Pennington et al., 2016). For example, Shapiro and Neuberg (2007) argued that the types of intrusive thoughts (i.e., a possible mechanism, see Schmader et al., 2008) generated by ST should be different depending on the target of threat. In self-as-target threat, self-based intrusive thoughts should increase while in group-as-target threat, group-based intrusive thoughts should increase. Therefore, when interpreting their results, future studies which investigate potential mediators and moderators should also consider the kinds of ST that they may manipulate In educational settings, students experiencing ST are motivated to disconfirm negative stereotypes about their group (e. g. gender, race, religion, parents' SES). In some case, this motivation itself tends to produce impaired performance (Brodish \& Devine, 2009). However, the consequences of ST go beyond the effect on performance (Spencer et al., 2016). Indeed, students who often experience ST could also be less confident about their own abilities (Muzzatti \& Agnoli, 2007) and show less task interest (Smith, Sansone, \& White, 2007) compared to their non-stereotyped counterparts. ST may also promote detachment from the threatened identity and disengagement from threatening domains. Our studies showed that ST can arise from any situational cue both in private or public evaluations. In public evaluations, which are likely to promote others-as-source ST, ST could be reduced by explicitly delineating achievement criteria (e.g., using a scoring scale, Jordan \& Lovett, 2007). Such a decision could help reduce potential biased judgments from the teachers and attenuate stigma consciousness for the students. Consequently, it may help teachers to create identity-safe classrooms. In private evaluations, which are likely to promote self-as-source ST, different strategies could be used to reduce ST: reducing the saliency of social identity, reducing stereotype awareness, or promoting self-affirmation (see Cohen \& Sherman, 2014). As a result, the identification of specific types of ST faced by an individual may be useful to address their peculiar effects and to better understand the necessary coping strategies (for an example, see Laurin, 2017). 


\section{References}

Abdi, H., \& Williams, L. J. (2010). Contrast analysis. In N. Salkind (Ed). Encyclopedia of Research Design (pp. 243-251). Thousand Oaks, CA: Sage.

Aronson, J., Lustina, M. J., Good, C., Keough, K., Steele, C. M., \& Brown, J. (1999). When White men can't do math: Necessary and sufficient factors in stereotype threat. Journal of Experimental Social Psychology, 35(1), 29-46. doi: 10.1006/jesp.1998.1371

Ambady, N., Shih, M., Kim, A., \& Pittinsky, T. L. (2001). Stereotype susceptibility in children: Effects of identity activation on quantitative performance. Psychological Science, 12(5), 385-390. doi: 10.1111/1467-9280.00371

Bagès, C., \& Martinot, D. (2011). What is the best model for girls and boys faced with a standardized mathematics evaluation situation: A hardworking role model or a gifted role model? British Journal of Social Psychology, 50(3), 536-543. doi: 10.1111/j.2044-8309.2010.02017.x

Berger, J., Cohen, B. P., \& Zelditch Jr, M. (1972). Status characteristics and social interaction. American Sociological Review, 37(3), 241-255. Retrieved from http://www.jstor.org/stable/2093465

Blascovich, J., Spencer, S., Quinn, D., \& Steele, C. (2001). African-Americans and high blood pressure: The role of stereotype threat. Psychological Science, 12(3), 225-229. doi: 10.1111/1467-9280.00340

Bonnot, V., \& Croizet, J.-C. (2007). Stereotype internalization and women's math performance: The role of interference in working memory. Journal of Experimental Social Psychology, 43(6), 857-866. doi: 10.1016/j.jesp.2006.10.006

Bosson, J. K., Haymovitz, E. L., \& Pinel, E. C. (2004). When saying and doing diverge: The effects of stereotype threat on self-reported versus non-verbal anxiety. Journal of Experimental Social Psychology, 40(2), 247-255. doi: 10.1016/S00221031(03)00099-4

Bourguignon, D., Desmette, D., Yzerbyt, V., \& Herman, G. (2007). Stereotype activation, intellectual performance and action tendencies: The case of unemployed people. International Review of Social Psychology, 20(4), 123-153.

Brauer, M., \& McClelland, G. (2005). L'utilisation des contrastes dans l'analyse des données: Comment tester les hypothèses spécifiques dans la recherche en psychologie? [The use of contrasts in data analysis: How to test specific hypotheses in psychological research?]. L'année Psychologique, 105, 273-305.

Brodish, A. B., \& Devine, P. G. (2009). The role of performance-avoidance goals and worry in mediating the relationship between stereotype threat and performance. Journal of Experimental Social Psychology, 45, 180-185. doi: 10.1016/j.jesp.2008.08.005

Cadinu, M., Maass, A., Frigerio, S., Impagliazzo, L., \& Latinotti, S. (2003). Stereotype threat: The effect of expectancy on performance. European Journal of Social Psychology, 33(2), 267-285. doi: 10.1002/ejsp.145

Carels, R. A., Burmeister, J., Oehlhof, M. W., Hinman, N., LeRoy, M., Bannon, E., \& Ashrafloun, L. (2013). Internalized weight bias: ratings of the self, normal weight, and obese individuals and psychological maladjustment. Journal of Behavioral Medicine, 36(1), 86-94. doi: 10.1007/s10865-012-9402-8

Chalabaev, A., Sarrazin, P., Stone, J., \& Cury, F. (2008). Do achievement goals mediate stereotype threat? An investigation on females' soccer performance. Journal of Sport and Exercise Psychology, 30, 143-158. Retrieved from https://www.ncbi.nlm.nih.gov/pubmed/18490787

Cohen, G. L., \& Sherman, D. K. (2014). The psychology of change: Self-affirmation and social psychological intervention. Annual Review of Psychology, 65, 333-71. doi: 10.1146/annurev-psych-010213-115137

Desombre, C., Anegmar, S., \& Delelis, G. (2018). Stereotype threat among students with disabilities: The importance of the evaluative context on their cognitive performance. European Journal of Psychology of Education, 33(2), 1-14. doi: 10.1007/s10212-016-0327-4

Doyle, R. A., \& Voyer, D. (2016). Stereotype manipulation effects on math and spatial test performance: A meta-analysis. Learning and Individual Differences, 47, 103-116. doi: 10.1016/j.lindif.2015.12.018

Fiske, S. T., Cuddy, A. J., Glick, P., \& Xu, J. (2002). A model of (often mixed) stereotype content: Competence and warmth respectively follow from perceived status and competition. Journal of Personality and Social Psychology, 82(6), 878-902. doi: 10.1037/0022-3514.82.6.878

Flore, P. C. \& Wicherts, J. M. (2015). Does stereotype threat influence performance of girls in stereotyped domains? A meta-analysis. Journal of School Psychology, 53(1), 25-44. doi: 10.1016/j.jsp.2014.10.002

Inzlicht, M., \& Ben-Zeev, T. (2003). Do high-achieving female students underperform in private? The implications of threatening environments on intellectual processing. Journal of Educational Psychology, 95(4), 796-805. doi: 10.1037/00220663.95.4.796

Jordan, A. H., \& Lovett, B. J. (2007). Stereotype threat and test performance: A primer for school psychologists. Journal of School Psychology, 45(1), 45-59. doi: 10.1016/j.jsp.2006.09.003

Kray, L. J., Thompson, L., \& Galinsky, A. (2001). Battle of the sexes: Gender stereotype confirmation and reactance in negotiations. Journal of Personality and Social Psychology, 80(6), 942-958. doi: 10.1037/0022-3514.80.6.942 
Koenig, A. M., \& Eagly, A. H. (2005). Stereotype threat in men on a test of social sensitivity. Sex Roles, 52(7-8), 489-496. doi: $10.1007 / \mathrm{s} 11199-005-3714-\mathrm{x}$

Laidra, K., Pullmann, H., \& Allik, J. (2007). Personality and intelligence as predictors of academic achievement: A cross-sectional study from elementary to secondary school. Personality and Individual Differences, 42(3), 441-451. doi: 10.1016/j.paid.2006.08.001

Lamont, R. A., Swift, H. J., \& Abrams, D. (2015). A review and meta-analysis of age-based stereotype threat: Negative stereotypes, not facts, do the damage. Psychology and Aging, 30(1), 180-193. doi: 10.1037/a0038586

Larkin, J. E., \& Pines, H. A. (2011). Anticipating public performance: Do women fear appearing intellectually less able? Journal of Applied Social Psychology, 41(3), 682-698. doi: 10.1111/j.1559-1816.2011.00732.x

Laurin, R. (2017). Group and individual stereotype threat and identity management strategies: An investigation of rugby women. Journal of Applied Social Psychology, 47(10), 584-588. doi: 10.1111/jasp.12466

Leyens, J. P., Désert, M., Croizet, J. C., \& Darcis, C. (2000). Stereotype threat: Are lower status and history of stigmatization preconditions of stereotype threat? Personality and Social Psychology Bulletin, 26(10), 1189-1199. doi: $10.1177 / 0146167200262002$

Lysaker, P. H., Tsai, J., Yanos, P., \& Roe, D. (2008). Associations of multiple domains of self-esteem with four dimensions of stigma in schizophrenia. Schizophrenia Research, 98(1-3), 194-200. doi: 10.1016/j.schres.2007.09.035

Maass, A., D'Ettole, C., \& Cadinu, M. (2008). Checkmate? The role of gender stereotypes in the ultimate intellectual sport. European Journal of Social Psychology, 38(2), 231-245. doi: 10.1002/ejsp.440

Martens, A., Johns, M., Greenberg, J., \& Schimel, J. (2006). Combating stereotype threat: The effect of self-affirmation on women's intellectual performance. Journal of Experimental Social Psychology, 42(2), 236-243. doi: 10.1016/j.jesp.2005.04.010

Muzzatti, B., \& Agnoli, F. (2007). Gender and mathematics: attitudes and stereotype threat susceptibility in Italian children. Developmental psychology, 43(3), 747-759. doi: 10.1037/0012-1649.43.3.747

Nguyen, H.-H. D., \& Ryan, A. M. (2008). Does stereotype threat affect test performance of minorities and women? A meta-analysis of experimental evidence. Journal of Applied Psychology, 93(6), 1314-1334. doi: 10.1037/a0012702 Oliveira, E. \& Cabral-Cardoso, C. (2017). Older workers' representation and age-based stereotype threats in the workplace. Journal of Managerial Psychology, 32(3), 254-268. doi: 10.1108/JMP-03-2016-0085

Orsini, A., Grossi, D., Capitani, E., Laiacona, M., Papagno, C., \& Vallar, G. (1987). Verbal and spatial immediate memory span: Normative data from 1355 adults and 1112 children. The Italian Journal of Neurological Sciences, 8(6), 537-548. doi: 10.1007/BF02333660

Pansu, P., Régner, I., Max, S., Colé, P., Nezlek, J. B., \& Huguet, P. (2016). A burden for the boys: Evidence of stereotype threat in boys' reading performance. Journal of Experimental Social Psychology, 65, 26-30. doi: 10.1016/j.jesp.2016.02.008

Pennington, C. R., Heim, D., Levy, A. R., \& Larkin, D. T. (2016). Twenty years of stereotype threat research: A review of psychological mediators. PLOS ONE, 11(1), e0146487. doi: 10.1371/journal.pone.0146487

Picho, K., Rodriguez, A., \& Finnie, L. (2013). Exploring the moderating role of context on the mathematics performance of females under stereotype threat: A meta-analysis. The Journal of Social Psychology, 153, 299-333. doi: 10.1080/00224545. 2012.737380 .

Raven, J., Raven, J. C., \& Court, J. H. (1998, updated 2003). Manual for Raven's Progressive Matrices and Vocabulary Scales. Section 1: General Overview. San Antonio, TX: Harcourt Assessment.

Régner, I., Steele, J. R., Ambady, N., Thinus-Blanc, C., \& Huguet, P. (2014). Our future scientists: A review of stereotype threat in girls from early elementary school to middle school. International Review of Social Psychology, 27(3), 13-51.

Sackett, P. R., Hardison, C. M., \& Cullen, M. J. (2004). On interpreting stereotype threat as accounting for African American-White differences on cognitive tests. American Psychologist, 59(1), 7-13. doi: 10.1037/0003-066X.59.1.7

Scheier, M. F., \& Carver, C. S. (1977). Self-focused attention and the experience of emotion: Attraction, repulsion, elation, and depression. Journal of Personality and Social Psychology, 35(9), 625-636. doi: 10.1037/0022-3514.35.9.625

Schmader, T., Johns, M., \& Forbes, C. (2008). An integrated process model of stereotype threat effects on performance. Psychological Review, 115(2), 336-356. doi: 10.1037/0033-295X.115.2.336 Sekaquaptewa, D., \& Thompson, M. (2003). Solo status, stereotype threat, and performance expectancies: Their effects on women's performance. Journal of Experimental Social Psychology, 39(1), 68-74. doi:10.1016/S0022-1031(02)00508-5

Shapiro, J. R. (2011). Different groups, different threats: A multi-threat approach to the experience of stereotype threats. Personality and Social Psychology Bulletin, 37(4), 464-480. doi: 10.1177/0146167211398140

Shapiro, J. R. (2012). Types of threat: From stereotype threat to stereotype threats. In M. Inzlicht, \& T. Schmader. (Eds.), Stereotype threat: Theory, process, and application (pp. 71-88). Oxford, England: Oxford University Press.

Shapiro, J. R., \& Aronson, J. (2013). Stereotype threat. In C. Stangor \& C. S. Crandall (Eds.) Stereotyping and Prejudice (pp. 95-118). Taylor and Francis. doi: 10.4324/9780203567708 
Shapiro, J. R., \& Neuberg, S. L. (2007). From stereotype threat to stereotype threats: Implications of a multi-threat framework for causes, moderators, mediators, consequences, and interventions. Personality and Social Psychology Review, 11(2), 107-130. doi: 10.1177/1088868306294790

Simon, B., \& Hamilton, D. L. (1994). Self-stereotyping and social context: The effects of relative in-group size and in-group status. Journal of Personality and Social Psychology, 66(4), 699-711. doi: 10.1037/0022-3514.66.4.699

Smith, J. L., Sansone, C., \& White, P. H. (2007). The stereotyped task engagement process: The role of interest and achievement motivation. Journal of Educational Psychology, 99(1), 99-114. doi: 10.1037/0022-0663.99.1.99

Spencer, S. J., Logel, C., \& Davies, P. G. (2016). Stereotype threat. Annual Review of Psychology, 67, 415-437. doi: 10.1146/annurev-psych-073115-103235

Spencer, S. J., Steele, C. M., \& Quinn, D. M. (1999). Stereotype threat and women's math performance. Journal of Experimental Social Psychology, 35(1), 4-28. doi: 10.1006/jesp.1998.1373

Steele, C. M. (1997). A threat in the air: How stereotypes shape intellectual identity and performance. American Psychologist, 52(6), 613-629. doi: 10.1037/0003-066X.52.6.613

Steele, C. M., \& Aronson, J. (1995). Stereotype threat and the intellectual test performance of African Americans. Journal of Personality and Social Psychology, 69(5), 797-811. doi: 10.1037/0022-3514.69.5.797

Stoet, G., \& Geary, D. C. (2012). Can stereotype threat explain the gender gap in mathematics performance and achievement? Review of General Psychology, 16, 93-102. doi:10.1037/a0026617

Stone, J. (2002). Battling doubt by avoiding practice: The effects of stereotype threat on self-handicapping in White athletes. Personality and Social Psychology Bulletin, 28(12), 1667-1678. doi: 10.1177/014616702237648

Stone, J., Lynch, C. I., Sjomeling, M., \& Darley, J. M. (1999). Stereotype threat effects on Black and White athletic performance. Journal of Personality and Social Psychology, 77(6), 1213-1227. doi: 10.1037/0022-3514.77.6.1213

Wout, D., Danso, H., Jackson, J., \& Spencer, S. (2008). The many faces of stereotype threat: Group-and self-threat. Journal of Experimental Social Psychology, 44(3), 792-799. doi: 10.1016/j.jesp.2007.07.005

Zhang, S., Schmader, T., \& Hall, W. M. (2013). L'eggomy ego: Reducing the gender gap in math by unlinking the self from performance. Self and Identity, 12(4), 400-412. doi: 10.1080/15298868.2012.687012

\section{Acknowledgements}

We would like to acknowledge Dr. Cristina Aelenei, Dr. Mathilde Lamotte, and Wendy Stevenson for their careful reading, advices and time. Additionally, we would like to thank the Ecole Supérieure du Professorat et de l'Education Lille Nord de France for their support. 